\title{
Uma análise sobre o público frequentador de museus e centros culturais: estudo de caso a partir do Centro Cultural Justiça Federal 1
}

\section{Un análisis sobre el público frecuentador de museos y centros culturales: estudio de caso a partir del Centro Cultural Justiça Federal}

\section{An analysis of the public attending museums and cultural centers: a case study from the Centro Cultural Justiça Federal}

\author{
Julyana Maia Corrêa ${ }^{2}$
}

\begin{abstract}
Resumo
O presente artigo busca averiguar o quantitativo de público de museus e centros culturais, a fim de realizar uma análise de seus consumidores. Pretende-se expor os motivos pelos quais essas instituições atingem apenas a um determinado grupo social, não sendo distribuída espacialmente de forma equânime, sendo visível a maneira desigual da distribuição de equipamentos culturais pela cidade do Rio de Janeiro.

$\mathrm{O}$ meu interesse por esse tema de pesquisa é demonstrar, através do entrecruzamento entre a fundamentação teórica e dos dados obtidos na pesquisa de campo, a necessidade da democratização do acesso a bens culturais, principalmente públicos. Para tanto, tomarei como objeto de estudo o Centro Cultural Justiça Federal (CCJF), instalado em um edifício histórico, de arquitetura imponente, na região central do Rio de Janeiro, atraindo olhares e o turismo para a instituição.
\end{abstract}

Palavras-Chave: Cultura; Democratização; Espaço Público; Museu.

\section{Resumen}

El presente artículo busca averiguar el cuantitativo de público de museos y centros culturales, a fin de realizar un análisis de sus consumidores. Se pretende exponer los motivos por los cuales esas instituciones alcanzan sólo a un determinado grupo social, no siendo distribuida espacialmente de forma equitativa, siendo visible la manera desigual de la distribución de equipamientos culturales por la ciudad de Río de Janeiro.

Mi interés por este tema de investigación es demostrar, a través del entrecruzamiento entre la fundamentación teórica y los datos obtenidos en la investigación de campo, la necesidad de la democratización del acceso a bienes culturales, principalmente públicos. Para ello, tomaré como objeto de estudio el Centro Cultural Justicia Federal (CCJF), instalado en un edificio histórico, de arquitectura imponente, en la región central de Río de Janeiro, atrayendo miradas y el turismo hacia la institución.

Palabras claves: Espacio Público; la cultura; la democratización; Museo.

\footnotetext{
${ }^{1}$ Artigo apresentado no Simpósio Temático Jovens Pesquisadores Latino-Americanos durante o II Seminário Latino-Americano de Estudos em Cultura - SEMLACult em Foz do Iguaçu/PR, Brasil, 2018.

${ }^{2}$ Graduanda do curso de Bacharel em Produção Cultural; Instituto Federal de Educação, Ciência e Tecnologia do Rio de Janeiro - IFRJ; Nilópolis, Rio de Janeiro, Brasil; julyana.mcorrea@gmail.com.
} 


\begin{abstract}
The present article seeks to ascertain the quantitative audience of museums and cultural centers in order to carry out an analysis of their consumers. The purpose is to explain the reasons why these institutions reach only a certain social group, not being distributed spatially in an equitable way, and the unequal distribution of cultural equipment by the city of Rio de Janeiro is visible. My interest in this research topic is to demonstrate the need to democratize access to cultural goods, especially public ones, through a cross-link between the theoretical basis and the data obtained in field research. To do so, I will take as object of study the Centro Cultural Justiça Federal (CCJF), housed in a historic building of imposing architecture, in the central region of Rio de Janeiro, attracting sights and tourism to the institution.
\end{abstract}

Keywords: Culture; Democratization; Public Space; Museum.

\title{
1. Introdução
}

Conforme o Estatuto de Museus, Lei no 11.904, de 14 de janeiro de 2009, diz que:

Consideram-se museus, para os efeitos desta Lei, as instituições sem fins lucrativos que conservam, investigam, comunicam, interpretam e expõem, para fins de preservação, estudo, pesquisa, educação, contemplação e turismo, conjuntos e coleções de valor histórico, artístico, científico, técnico ou de qualquer outra natureza cultural, abertas ao público, a serviço da sociedade e de seu desenvolvimento.

Os museus e centros culturais possuem interesses semelhantes, apesar da metodologia aplicada por cada um para atingir esse objetivo seja divergente "essas instituições almejam contribuir para o desenvolvimento humano e social das comunidades nas quais estão inseridas." (KÖPTCKE; CAZELLI; LIMA, 2008, p.13)

A história produzida nos museus, com base nas teorias do IHGB - Instituto Histórico Geográfico Brasileiro -, visava a garantir a homogeneidade de pensamento no interior da nação, no sentido de congregar em torno de um referencial comum - neste caso, o passado - grupos sociais altamente diversificados culturalmente. (FIGUEIREDO; VIDAL, 2012, p. 148).

Com a pesquisa em andamento, é possível levantar algumas questões necessárias para seu desenvolvimento e aplicação mais consistente e funcional dentro dessas instituições. As instituições limitam o público? O público se sente, de alguma forma, oprimido ao frequentar essas instituições, seja pelas suas atividades, exposições ou arquitetura? Frequentar essas instituições vem de um hábito enraizado ou surge a partir do momento que se toma a consciência da importância cultural que museus e centros culturais carregam consigo? O 
público que frequenta esses espaços estão democraticamente inseridos socialmente? $\mathrm{Ou}$ apenas uma determinada classe social tem acesso e interesse por essas instituições?

\section{Educação museal}

O trecho da obra Museus dos Gabinetes de Curiosidades à Museologia Moderna (FIGUEIREDO; VIDAL, 2013), reforça a ideia de que os museus possuem um papel fundamental na formação da sociedade. Através desses museus, a possibilidade de refletir sobre a história da humanidade é trazida de forma diferente do que é mostrado nos livros de História. Porém, o público frequentador desses espaços era uma parcela limitada, fazendo com que, de algum modo, este fato se tornasse uma problemática. Os museus eram frequentados por essa parcela da sociedade, justificado por este limitar o acesso do público, ou essa parte excluída não se sentia pertencente a esse local? O museu limitava ou a sociedade não se sentia atraída por tal espaço?

É possível identificar a importância de se criar um hábito durante o processo de formação do ser, para que seja possível perpetuar-se durante a fase adulta. A partir da

Construção do consenso social e político sobre a importância de democratizar o acesso aos bens da cultura 'legítima' os dados sobre visitas aos museus reafirmam que o acesso a essas instituições permanece restrito, principalmente em função da relação entre capital cultural escolar e predisposição às práticas e bens culturais cultivados. (BOURDIEU E DARBEL, 1969, 2003; DONNAT, 1973, 1997; MIRONER, 2003; ALMEIDA, 2003).

De acordo com o estudo de caso feito é possível notar que o nível de escolaridade é um dos aspectos mais consideráveis ao analisar o público das instituições com vertentes museais, o que faz concluir que o nível de instrução (academicamente falando) está diretamente ligado com o consumo e conscientização do bem cultural público.

Por outro lado, a retórica da democratização segue social e politicamente relevantes, buscando explicitar a existência e diminuir o impacto das desigualdades sociais face à cultura. Tal busca enfatiza a importância do acesso e da apropriação da cultura legitimada para a inclusão dos excluídos ou para a mobilidade dos menos abastados no espaço social. Alguns autores observam que a promoção da cultura é desenvolvida por uma rede de instâncias culturais. Os museus, ambientes que favorecem intensa interação social, vêm ocupando lugar de destaque nessa rede. (KÖPTCKE; CAZELLI; LIMA, 2008, p.12) 


\section{Objeto de estudo: Centro Cultural Justiça Federal}

O edifício do Centro Cultural Justiça Federal (CCJF), localizado a Avenida Rio Branco, $n^{\circ}$ 241, na Cinelândia, região central do município do Rio de Janeiro, foi arquitetado por Adolpho Morales de Los Rios. O arquiteto espanhol também fez o projeto de mais vinte e um edifícios pela mesma avenida, a então Av. Central projetada pelo engenheiro Paulo de Frontin.

A construção do edifício começou em 1905, e num primeiro momento, comportaria a Mitra Arquiepiscopal do Rio de Janeiro, tendo como autoridade máxima Cardeal Arcoverde.

Com a recém criação do Judiciário Federal e com o atual aspecto político, a República, via-se a necessidade de adquirir um local mais adequado e espaçoso para ocupar a sede do Supremo Tribunal Federal (STF), criado em 11 de outubro de 1890. O Ministro da Justiça e Negócios Interiores do governo de Afonso Pena, buscou um novo endereço para o STF na recém-inaugurada Avenida Central e negociou o edifício para a tutela do governo em 1907.

Com o edifício sendo adquirido pelo órgão federal, ocorreram algumas mudanças no projeto inicial, e como a construção já estava em estágio avançado, as alterações ocorreram a partir do $3^{\circ}$ pavimento e descaracterizando a fachada religiosa, ganhando características mais marcantes do renascimento francês.

Ainda quem entra no edifício consegue perceber alguns traços do que deveria ter sido um patrimônio religioso, pela grande quantidade de vitrais, principalmente o vitral da Rosácea, muito comum nas igrejas católicas, e pelas paredes pintadas na Sala de Sessões, com a Deusa da Justiça. Em 03 de abril de 1909 foi inaugurado o edifício da nova sede do Tribunal, caracterizado por uma arquitetura eclética muito comum à época no Rio de Janeiro.

O edifício tem como vizinho a Biblioteca Nacional, o Theatro Municipal do Rio de Janeiro, Palácio Pedro Ernesto (sede da Câmara Municipal dos Vereadores do Rio de Janeiro) e o Museu Nacional de Belas Artes, também projetado por Adolpho Morales de Los Rios. O projeto desses edifícios ao entorno da Praça Ferreira Viana (em 1910, Praça Floriano), se deu a partir do processo de revitalização do então Distrito Federal.

O prefeito da época, Francisco Pereira Passos, foi nomeado pelo Presidente Rodrigues Alves, em 1902, e foi responsável por fazer da velha cidade colonial uma capital moderna.

De 02 de janeiro de 1903 a 15 de novembro de 1906 executou o "bota abaixo" na região a fim de remodelar a Capital da República. Criou um enorme boulervard que usou como referência a reforma urbana em Paris, uma vez que viu a necessidade de provocar melhores condições estéticas e higiênicas, por ser um local insalubre. 
Além dessa modernidade o então prefeito foi também o precursor do início da derrubada do Morro do Castelo para que fosse possível o aterramento de muitos pontos marítimos da cidade, com o intuito de melhorar a circulação da capital, conforme descrito.

A sede do STF permaneceu no endereço até 1960 quando mudou o Distrito Federal para Brasília. Logo após, o edifício foi ocupado pelo Supremo Tribunal Eleitoral, Tribunal de Alçada. Na década de 70 retomou para a Administração Federal com as Varas da Justiça Federal de $1^{\mathrm{a}}$ instância.

Durante décadas, após a sua inauguração, o edifício passou por diversas transformações a fim de se adequar para as necessidades dos órgãos ali instalados, e as modificações na identidade do edifício foram sendo feitas. Instalação de novos nichos para divisão interna, rebaixamento no teto e pintura das paredes foram algumas intervenções feitas.

Em 1988 o edifício foi interditado após o desabamento do teto de duas salas no térreo, pela falta de manutenção, inclusive a presença de um lençol freático provocou um princípio de afundamento do prédio, além de cupim no solo, permanecendo fechado até 1994. Nesse ano, foi o firmamento de convênio para a obra de restauração do espaço, entre o Tribunal Regional Federal da $2^{a}$ Região, o Instituto Herbert Levy e a Caixa Econômica Federal.

O período de restauração durou sete anos, e o edifício reabriu em 04 de abril de 2001, já como Centro Cultural Justiça Federal.

O momento que marca a então transformação do edifício histórico depredado com o tempo, para que seja restaurado e então transfigurar para centro cultural, se dá a partir do Desembargador Paulo Freitas Barata, então presidente do Tribunal Regional Federal da $2^{\mathrm{a}}$ Região, órgão responsável pelo edifício. Em entrevista a João Coelho no dia 16/08/2002, o mesmo comenta:

Durante a minha gestão como Presidente do Tribunal, iniciei os primeiros contatos para a recuperação do prédio; não tinha ideia de fazer uma restauração completa; restauraríamos o que fosse possível, tendo como objetivo torna-lo reutilizável, para que ali funcionasse um museu da Justiça ou um centro cultural. Não tinha muita clareza do que seria. Minha preocupação maior era a preservação do prédio. Entrei em contato com o Conselho da Justiça Federal, que mandou um arquiteto deles aqui. Ele começou a fazer as plantas, detalhar parte elétrica, parte hidráulica; fez a planta das áreas... Minha ideia era fazer a obra com recursos próprios da União Federal alocados à Justiça Federal. Quando saí da Presidência, os que me sucederam deram um enfoque diferente, procuraram fazer convênio com outras instituições e abandonaram o levantamento que havia sido feito pelo Conselho. (...) Cheguei a 
fazer uma demolição de parte do forro e do assoalho, que estavam infestados de cupins, no intuito de conter o problema. (COELHO, 2002, p. 18)

A ideia de escolher um centro cultural para ocupar um edifício histórico vem da influência europeia a partir da segunda metade do século XX, e no Brasil, mais especificamente, a partir do final da década de 80 e 90, convergindo com um período de grande renovação cultural. No mesmo conceito de "tempo de mudança", o Centro da cidade do Rio de Janeiro vê cada vez mais a necessidade de construir grandes edifícios para que desse conta do crescimento da região.

É nesse momento que é indispensável a percepção em conservar edificações históricas e patrimoniais, para salvar a identidade cultural daquela região. É nessa fase que nasce a criação do projeto de instauração do CCJF, reafirmando que "da perspectiva do planejamento urbano, esta ação relaciona-se não apenas à educação, formação da cidadania e produção de conhecimento, mas ao turismo 'de entretenimento e lazer', fonte de empregos e de lucro." (GUIMARÃES; IWATA, 2001).

A ideia de reutilização do edifício foi dada pelo Diretor do Foro José Ricardo de Siqueira Regueira, em 1990, já com a intenção de instalar um centro cultural que "estivesse aberto às mais diversas manifestações culturais e promovesse uma aproximação entre o Judiciário e a sociedade civil." (COELHO, 2002, p. 16).

O CCJF conta no Térreo, atualmente, com um Teatro que acomoda 141 pessoas; com uma sala de Cinema, acomodando 56 pessoas, sendo estes dois espaços possuindo acessibilidade para cadeirantes e cadeira especial para obesos; uma Sala de Leitura; e uma Sala de Cursos com 30 lugares. No primeiro andar possui Galerias para exposição, Foyer e a Sala de Sessões com a mobília original do STF de 1920, contando com 84 assentos. No segundo andar possui Galerias para exposição, uma Sala de Leitura com acesso à internet; e uma Biblioteca, que possui um acervo de aproximadamente 12.000 obras, incluindo livros técnicos sobre arte e fotografia. No terceiro andar funciona a parte administrativa do Centro Cultural. Todos os andares possuem banheiros e bebedouros para os visitantes.

O edifício do CCJF, além de ser público, é tombado pelo patrimônio histórico, dificultando algumas reestruturações. O tombamento de um imóvel faz garantir a preservação do espaço, restaurando e preservando o máximo do projeto original.

A preservação e proteção do patrimônio cultural é uma determinação constitucional, conforme se verifica no art. $216, \S \S 1^{\circ}$ e $4^{\circ}$, da Constituição da República de 1988 . O Decreto-lei n. ${ }^{\circ}$ 25/1937, documento que criou o instituto do tombamento no Brasil, em seu art. 17, determina que "as coisas tombadas não poderão, em caso nenhum, 
ser destruídas, demolidas ou mutiladas, nem, sem prévia autorização especial do Serviço do Serviço do Patrimônio Histórico e Artístico Nacional, ser reparadas, pintadas ou restauradas". (PEREIRA; LIMA, 2005, p. 39)

Todavia, é importante ressaltar, que como edifício público, o CCJF deve atender às normas de acessibilidade. Essa articulação deve ser feita analiticamente para atender as necessidades do local, sendo necessário levar em consideração esses dois aspectos que caracterizam o edifício.

Segundo o art. 11 da Lei Federal $\mathrm{n}^{\circ} 10.098 / 2000$, regulamentada pelo Decreto $\mathrm{n}^{\circ}$ 5.296/2004, a construção, ampliação ou reforma de edifícios de uso público e de uso coletivo devem atender aos preceitos de acessibilidade. Considera-se acessibilidade "a condição para utilização, com segurança e autonomia, dos espaços, mobiliário e equipamentos urbanos, das edificações, dos serviços de transporte e dos dispositivos, sistemas e meios de comunicação e informação, por pessoa portadora de deficiência ou com mobilidade reduzida". (Art. $2^{\circ}$ da Lei $\left.{ }^{\circ} 10.098 / 2000\right)$. (PEREIRA; LIMA, 2005, p. 39)

O edifício em questão, conta apenas com acessibilidade para cadeirantes nos ambientes do Térreo (Teatro e Cinema), não dispondo de um elevador com tamanho adequado para acesso aos outros andares e atividades. Entretanto, além do tombamento do edifício, é possível perceber a dificuldade das gestões para realizar as intervenções necessárias no edifício e proporcionar a acessibilidade em todo o CCJF, devido ao repasse de verba destinada ao Centro Cultural para a realização de obras de infraestrutura.

\section{Metodologia}

Bourdieu e Darbel acreditavam na "importância de democratizar o acesso aos bens da cultura". Com isso, a metodologia escolhida para este projeto foi o uso de pesquisas qualitativas, para que seja possível conhecer o público atingido pelo Centro Cultural e desse ponto conseguirmos ter base para possíveis questionamentos ao longo deste trabalho. Dessa forma é possível analisar que

No contexto atual, ganham relevância questões sobre a relação entre acesso à cultura e inserção na sociedade contemporânea. Reflexões sobre as práticas culturais cultivadas, entre elas a visita aos museus, colocaram para a sociologia muitas questões e algumas propostas sobre a natureza e o grau de importância de tais práticas nas diferentes sociedades, sobre o que as motiva e sobre a relação entre o 
acesso à cultura e a posição social de indivíduos e grupos. (KÖPTCKE,CAZELLI, LIMA, 2008, p.12)

Serão realizadas também entrevistas, no formato semi estruturada para que os objetivos sejam alcançados e as possíveis questões serem respondidas e refletidas de forma mais clara. Essas entrevistas serão comparadas com a última pesquisa de público feita pela instituição, em 2016, a fim de fazer uma análise do que mudou nos últimos anos, em termos de público e de gestão do espaço.

O tipo de observação será feita de maneira direta, já que para analisar o público frequentador dos espaços de museus é preciso compreender os motivos que os levam ou não até lá, concomitantemente com o público que não tem o hábito de frequentar determinados espaços culturais públicos.

Este trabalho está em processo de construção e ainda não foi possível chegar a resultados objetivos e conclusivos. O mesmo é a pesquisa para o Trabalho de Conclusão de Curso como parte dos requisitos necessários para a obtenção do título de bacharel em Produção Cultural.

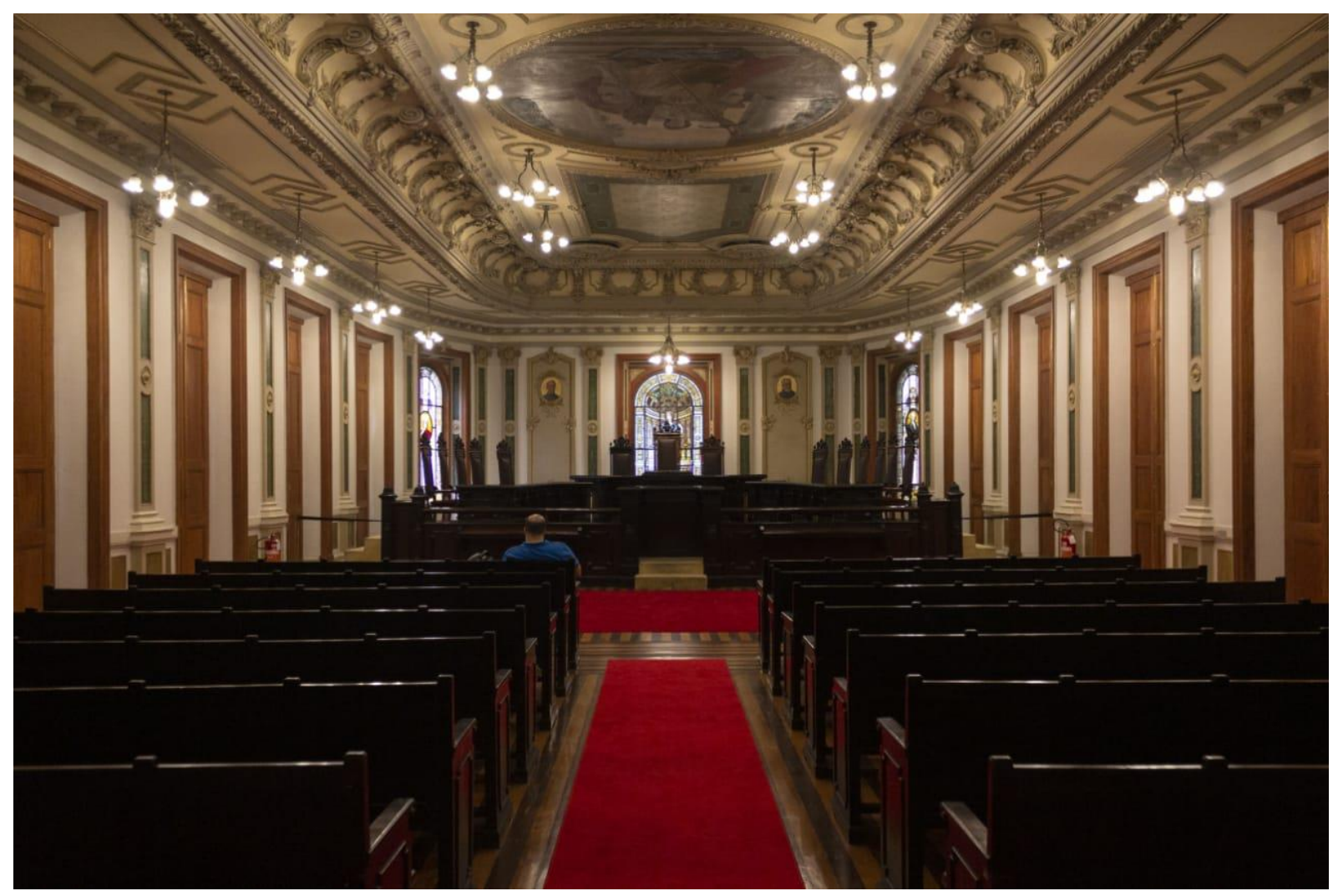

Fotografia 1 - Sala de Sessões com mobília original da antiga sede do STF

Fonte: Acervo pessoal | Foto: Caio Valadão 
RELACult - Revista Latino-Americana de Estudos em Cultura e Sociedade

Revista Latinoamericana de Estudios en Cultura y Sociedad | Latin American Journal of Studies in Culture and Society V. 05, ed. especial, mai., 2019, artigo no 1521 | claec.org/relacult | e-ISSN: 2525-7870

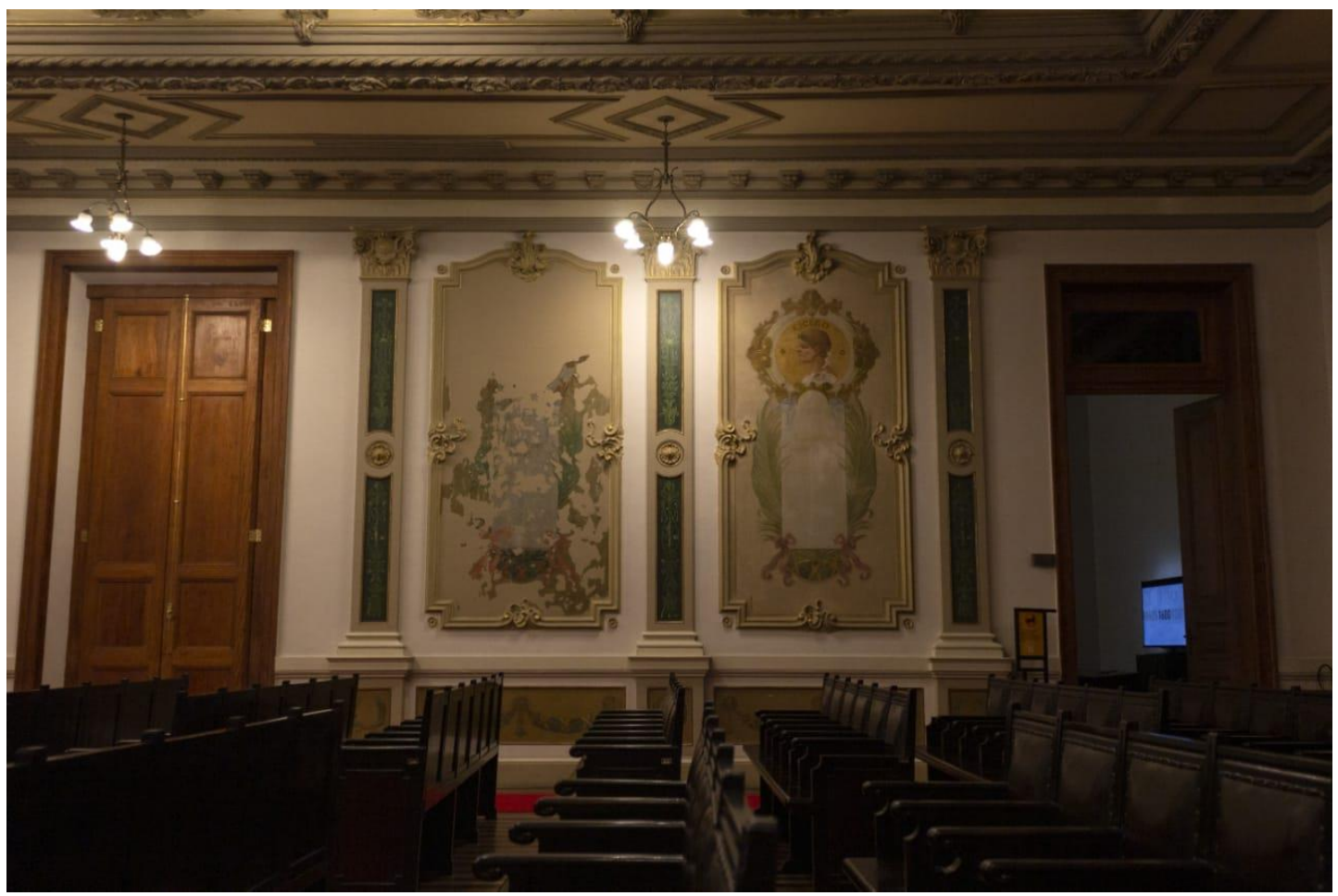

Fotografia 2 - Parede restaurada da Sala de Sessões

Fonte: Acervo pessoal | Foto: Caio Valadão

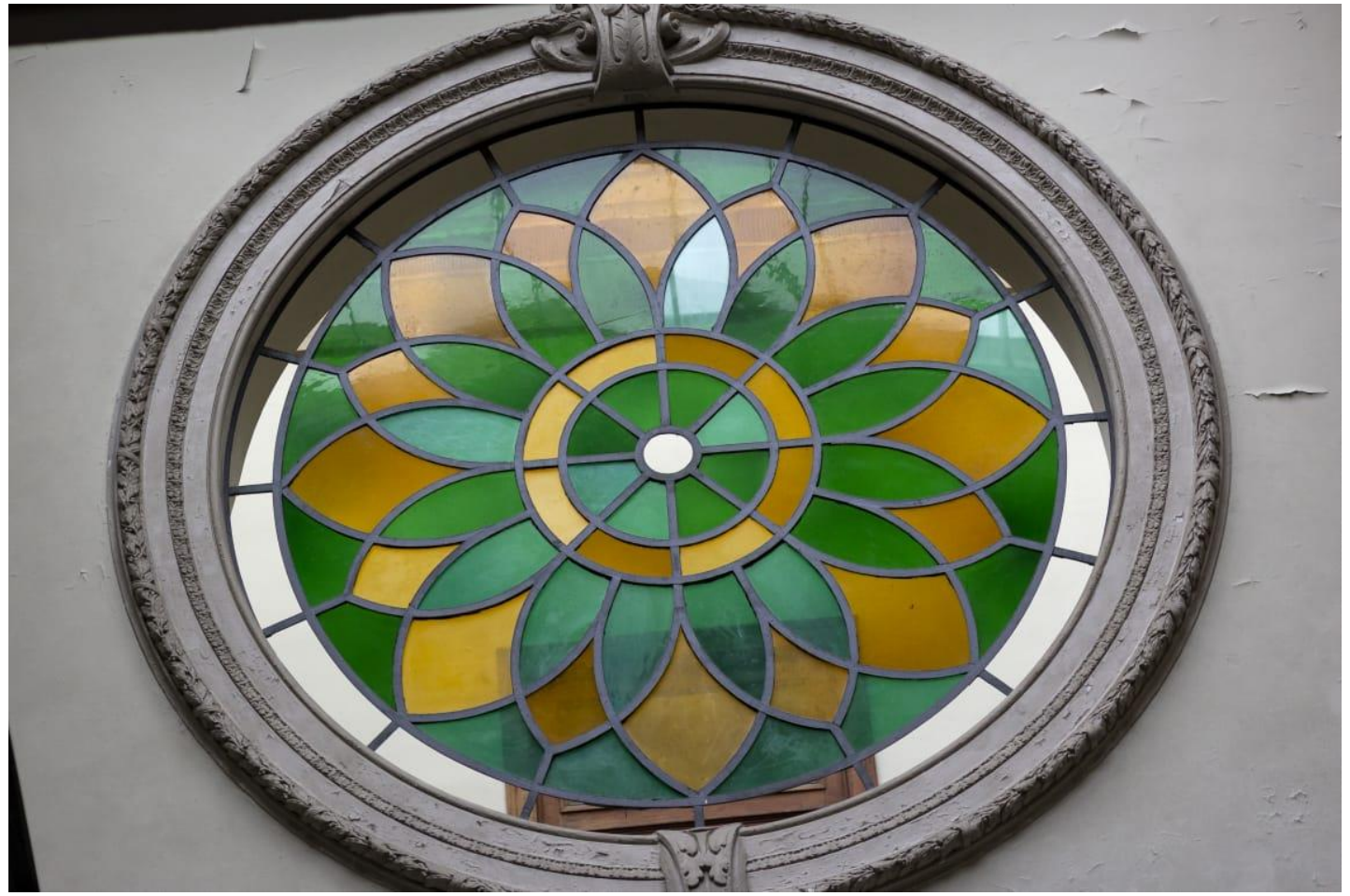

Fotografia 3 - Vitral Rosácea

Fonte: Acervo pessoal | Foto: Caio Valadão 


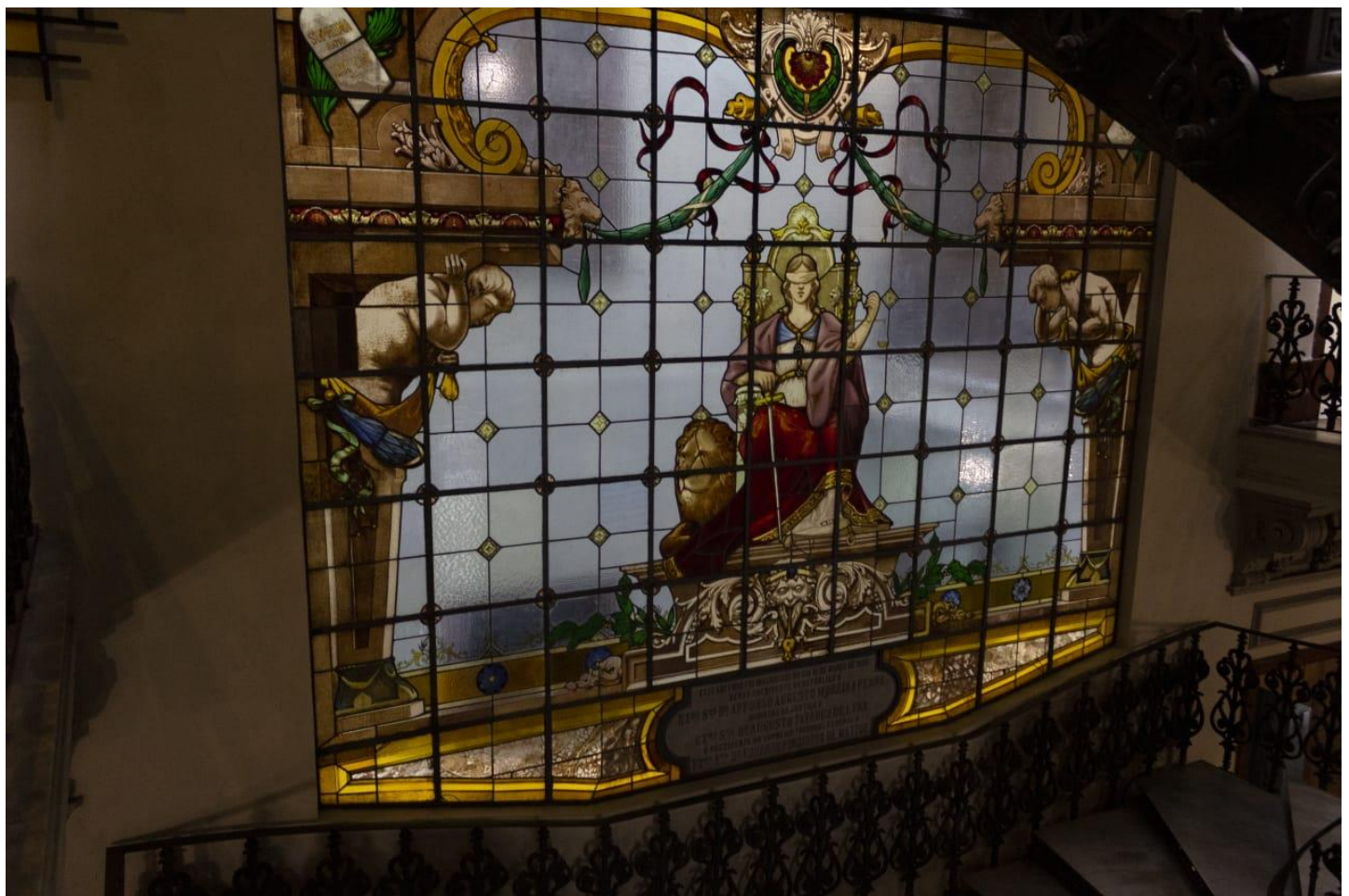

Fotografia 4: Vitral representação Deusa da Justiça localizada na escadaria principal Fonte: Acervo pessoal | Foto: Caio Valadão

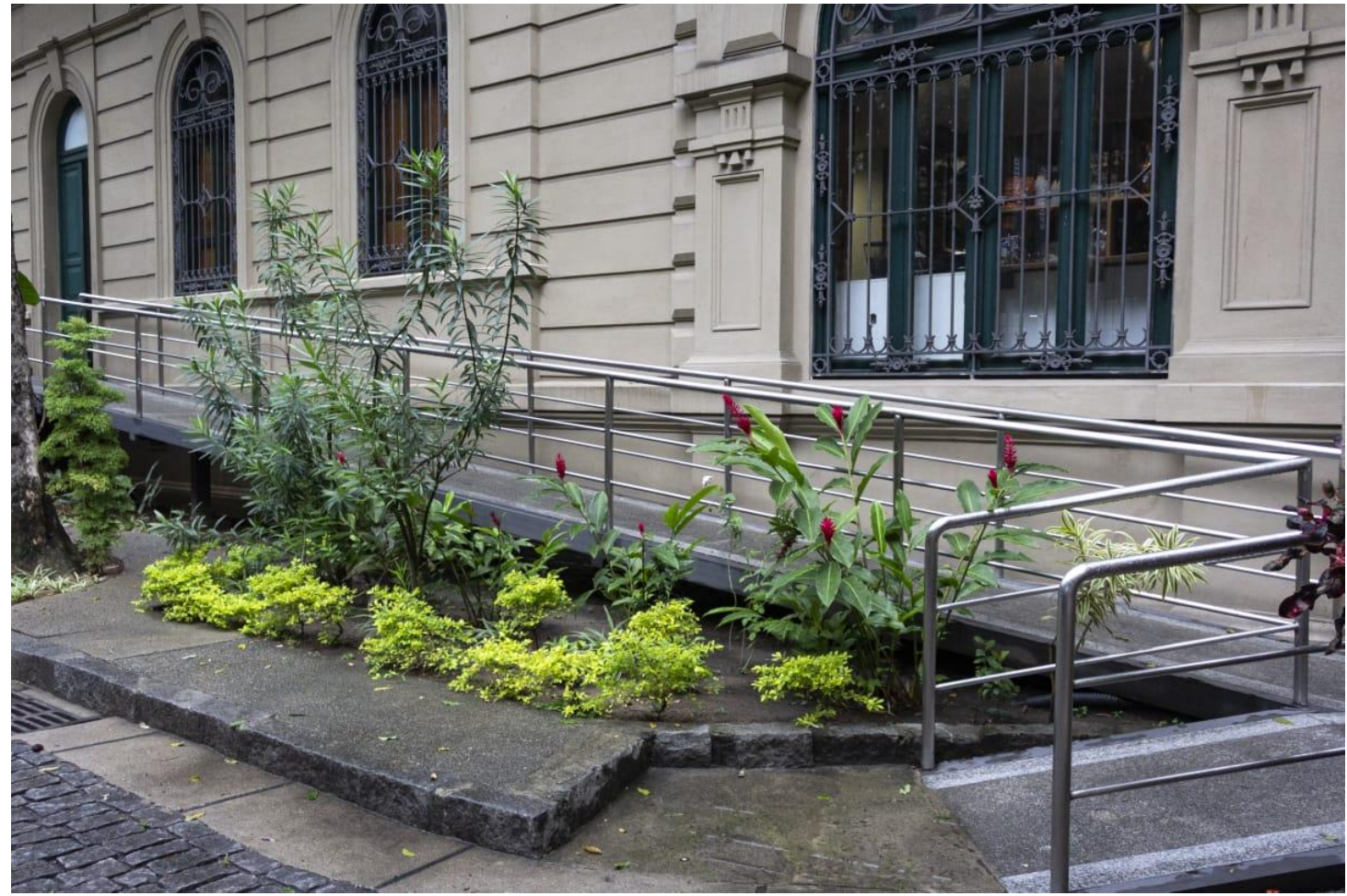

Fotografia 5: Rampa de acessibilidade localizada no estacionamento

Fonte: Acervo pessoal | Foto: Caio Valadão 


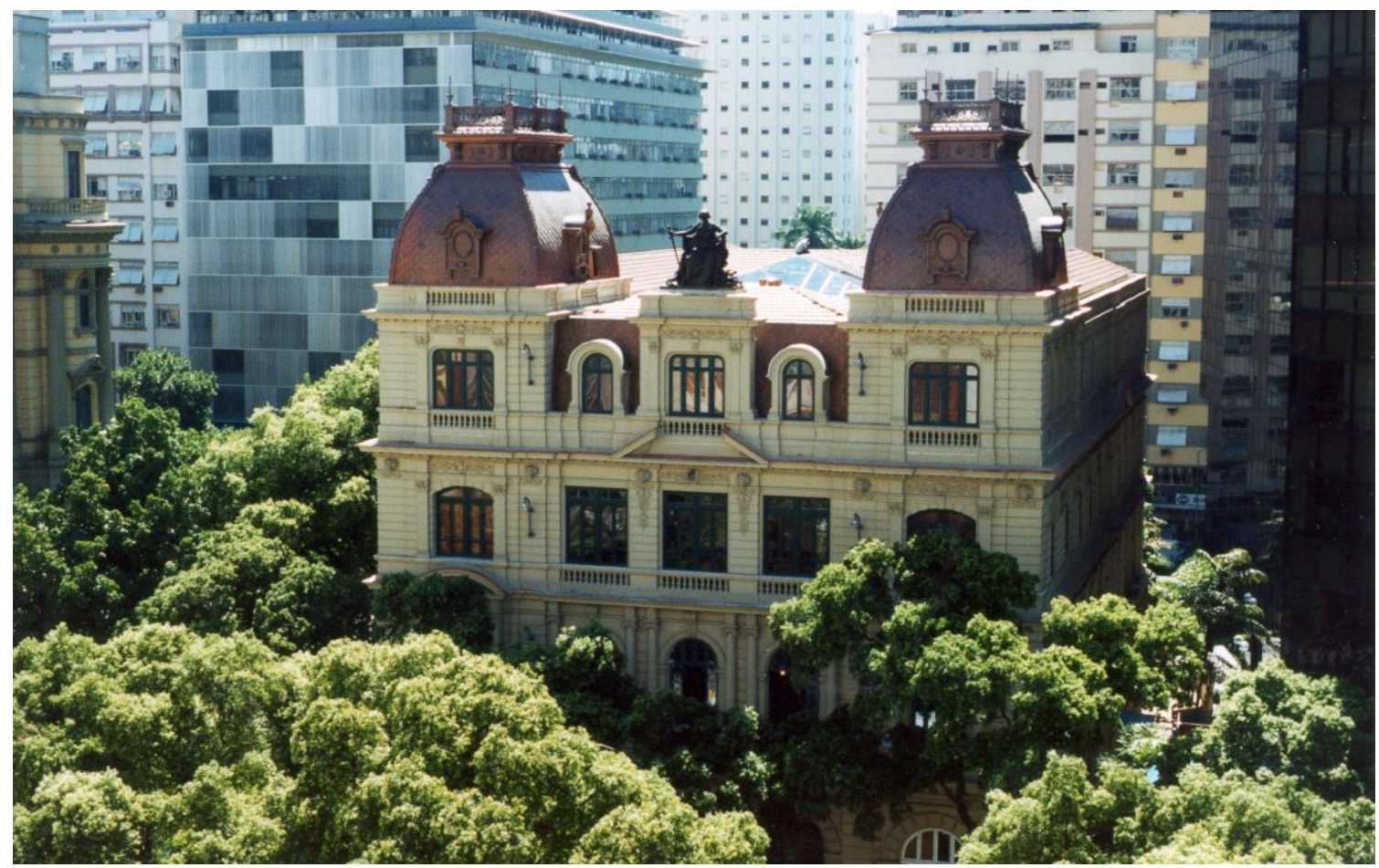

Fotografia 6: Fachada do Centro Cultural Justiça Federal

Fonte: www.museus.gov.br; publicação de 29/07/14; foto de divulgação

\section{Referências bibliográficas}

COELHO, João. O Centro Cultural Justiça Federal: Estudo sobre sua implantação. 2002. 63 f. Monografia (Bacharelado em Produção Cultural)- Universidade Federal Fluminense, Niterói RJ, 2002.

FIGUEIREDO, Betânia Gonçalves; VIDAL, Diana Gonçalves (Org.). Museus: dos Gabinetes de Curiosidades à Museologia Moderna. 2. ed. [S.1.]: Traço Fino, 2013. 250 p.

GUIMARAENS, Cêça; IWATA, Nara. A importância dos museus e centros culturais na recuperação de centros urbanos. 2001. Disponível em:

<http://www.vitruvius.com.br/revistas/read/arquitextos/02.013/881>. Acesso em: 12 jun. 2018.

KÖPTCKE, Luciana Sepúlveda; CAZELLI, Sibele; DE LIMA, José Matias. Museus e Seus Visitantes: Relatório de Pesquisa Perfil-Opinião 2005. 2005. ed. Brasília - Rio de Janeiro: [s.n.], 2008. 67 p.

PEREIRA, Ana Carolina Araújo; LIMA, Erlon de Paula. Acessibilidade em Imóveis Tombados. Publicação da Procuradoria-Geral de Justiça do Ministério Público do Estado de Minas Gerais - Ano 1 - no 3 - Análise Crítica de Anteprojeto de Código Brasileiro de Processos Coletivos. Dezembro de 2005 /Janeiro de 2006. 
WILDER, Gabriela Suzana. Inclusão Social e Cultural: Arte Contemporânea e Educação em Museus. São Paulo: UNESP, 2009. 165 p. 